\title{
The Symmetry Rule: A Seven-Year Study of Symptoms and Explanatory Labels Among GulfWar Veterans
}

\author{
Noel T. Brewer ${ }^{1,{ }^{*}}$, William K. Hallman ${ }^{2}$, and Howard M. Kipen ${ }^{3}$ \\ ${ }^{1}$ Department of Health Behavior and Health Education, University of North Carolina School of \\ Public Health, Chapel Hill, NC, USA \\ ${ }^{2}$ Department of Human Ecology, Rutgers University, USA \\ ${ }^{3}$ Environmental and Occupational Health Sciences Institute and Department of Environmental \\ and Community Medicine, University of Medicine and Dentistry, Robert Wood Johnson Medical \\ School, NJ, USA
}

\begin{abstract}
Noticing medical symptoms can cause one to search for explanatory labels such as "ate bad food" or even "exposed to anthrax," and perhaps these labels may cause new symptom reports. The present study examined whether there is empirical support for this symptom-label "symmetry rule." We interviewed veterans $(N=362)$ from the Gulf War Registry in 1995 and 2002 about their medical symptoms and about their exposure to war-related hazards and stressors. Health symptom reports were strongly correlated between the two time periods and showed relatively stable mean levels, whereas recall of war-related exposures was notably unstable. Veterans starting with fewer medical symptoms recalled fewer war-related exposures seven years later. Initial recollection of chemical and biological warfare exposure (but not other exposures) longitudinally predicted novel medical symptoms. The findings generally support the symmetry rule hypotheses, although the evidence for the label to symptom link was less strong. The findings account for some variability in symptoms and exposure recall over time, but they do not, on their own, account for the Gulf War veterans' elevated number of unexplained medical symptoms.
\end{abstract}

\section{Keywords}

Illness cognition; symmetry rule; symptom reporting; terrorism; war

\section{INTRODUCTION}

Psychologists have long recognized that symptom reports and cognition are linked (Cioffi, 1991; David \& Wesseley, 1995; Leventhal et al., 1980; Mechanic, 1972; Pennebaker, 1982). The symptom-cognition link is well illustrated by a recent controversy surrounding genetically modified corn. A consumer advocacy group reported that traces of a protein 
unique to a particular strain of genetically modified corn was present in taco shells and other foods consumed by humans, even though industry spokespersons had assured the public that the corn was used only as cattle feed. News of the tainted food traveled quickly. Soon, the Centers for Disease Control (CDC, 2001) had received reports from 51 individuals reporting symptoms they believed were related to exposure to the corn. The symptoms ranged from mild (weakness and dizziness) to severe (loss of consciousness and hospitalization).

However, an exhaustive investigation that included in-depth interviews and serologic testing concluded that none were exposed to the genetically modified corn (CDC, 2001) and that an allergic reaction related to the exposure did not explain the reported symptoms. So what happened?

This question is of particular interest to health psychologists both as an exemplar of similar public health phenomena and for the theoretical questions it raises. Among numerous potential explanations, two seem likely, and they are not mutually exclusive. First, it may be that people with existing unexplained symptoms found a useful explanation in the news reports of genetically modified corn in the food supply. Second, the news may have prompted some who believed that they had consumed the corn (and thus labeled themselves as having been "exposed") to become vigilant for symptoms of allergic reaction (e.g., Barsky \& Borus, 1999; Baumann et al., 1989; Brewer et al., 2002).

These two theoretical explanations provide the basis for the symmetry rule (Brownlee et al., 2000). As an extension of the self-regulation model, Leventhal and colleagues posited that cognitions about illness have dual representations in memory: one is concrete and the other abstract (Brownlee et al., 2000). In particular, they argue that the identity of a health state involves an abstract label (e.g., ate food containing genetically modified corn) and concrete symptoms (e.g., weak, dizzy, nauseous), and that the presence of either of the representations will give rise to the other. Thus, "people will seek and find labels to explain their symptoms and seek and find symptoms to concretize (i.e., make sense of) their illness labels" (Brownlee et al., 2000, p. 388).

Numerous studies show support for the symmetry rule. A particularly fruitful line of this research concerns hypertension (Blumhagen, 1980) and hypercholesterolemia. The two diseases are characterized, respectively, by chronically elevated blood pressure and cholesterol, elevations that do not vary with physical symptoms (Baumann \& Leventhal, 1985; but see Pennebaker \& Watson, 1989). Meyer et al. (1985) found that $80 \%$ of hypertensive patients $(N=55)$ in ongoing treatment believed that the illness is asymptomatic, and yet $88 \%$ of them believed that they could tell when their own blood pressure was elevated. Interviews with another group of patients new to treatment $(N=65)$ showed that the proportion reporting hypertensive symptoms increased from $71 \%$ to $92 \%$ over a six-month period. This evidence supports the claim that a label (hypertension) gives rise to congruent symptom reports.

Additional support for the claim is offered by an experiment in which participants were randomly assigned to receive false feedback that they had normal or high blood pressure (Baumann et al., 1989; see also Croyle \& Sande, 1988). The high blood pressure group reported more symptoms people often associate with hypertension, such as fast heartbeat 
and dizziness, as having occurred over the past three months. At the same time, the two groups reported an equivalent number of nonhypertension symptoms such as nasal congestion and loss of appetite. The short timeframe of the experiment (10 minutes) suggests that the experimental group were unlikely to have developed new symptoms but instead had better access to their memory of such experiences.

Nonetheless, symptoms engendered by illness labels are experienced as real and have serious consequences for behavior. Brewer et al. (2002) examined a sample of 169 patients taking medication to lower their chronically elevated low density lipoprotein cholesterol levels. Patients who believed that they could tell when their cholesterol levels were high were less successful in controlling their cholesterol. The erroneously attributed symptoms appeared to be part of an integrated model of their disease characterized by other erroneous beliefs including the cyclic rather than chronic nature of high cholesterol. Some poorly adherent patients appeared to be taking their medication to ameliorate their spuriously attributed symptoms.

The symmetry rule's other claim - that symptoms prompt a search for a label-is also well supported (e.g.,Mechanic, 1972). People who do not feel well discuss symptoms with friends, search the Internet, visit doctors, and so on, all in search of an illness label. Misattributions of symptoms can lead to inappropriate underutilization (Siegel et al., 1999) and overutilization of health services (Barsky et al., 2001). Some patients with unexplainable medical symptoms continue to search for confirmation of a specific illness label despite repeated medical advice that no appropriate label exists (Hodgson \& Kipen, 1999; Sigal \& Hasset, 2002). In its most extreme form, such searching takes on a pathological dimension, as in hypochondriasis (Barsky \& Klerman, 1983), but far more common is the periodic use of medical services that is a routine and even desirable aspect of managing one's health.

\subsection{The Present Study}

The present study examined whether there was support over the long term for the symmetry rule, particularly the prediction that a label can cause new symptom reports. We chose to study Persian Gulf War veterans because of their elevated reports of unexplained medical and psychological symptoms (Iowa Persian Gulf Study Group, 1997). Indeed, the Centers for Disease Control case definition for Gulf War Syndrome is defined solely by selfreported, unexplained symptoms from three clusters: fatigue, mood-cognition, and musculoskeletal (Fukuda et al., 1998; Hallman et al., 2003).

A leading theory about the cause of the veterans' symptoms is exposure to chemical and biological warfare. Studies have shown that most soldiers were unlikely to have been exposed to such agents and that their pattern of medically diagnosable conditions were not consistent with exposures (Fukuda et al., 1998; Gray et al., 1999, 2002; for a review, see Hodgson \& Kipen, 1999; but see Shapiro et al., 2002). Clinical investigations of the major bodily systems have not revealed underlying pathology to explain the symptoms of a majority of ill Gulf War veterans (Fukuda et al., 1998; Hodgson \& Kipen, 1999; Wessely, 2001). Some have suggested that chemical-warfare-induced neurological impairments 
explain Gulf War illnesses (e.g., Haley\&Kurt, 1997), but this theory is not presently in the mainstream of thinking about these illnesses (Couzin, 2006).

However, many Gulf War veterans steadfastly believe they were exposed to chemical and biological weapons. Such beliefs make sense in a context in which they were repeatedly warned of and trained to protect themselves against chemical and biological warfare agents. There is remarkably little published, peer-reviewed research that has attempted to corroborate the veterans' recall with their deployment records, although the U.S.

Department of Defense has made several detailed case analyses of exposure reports available in which they conclude that there were no self-reported exposures events for which there was definitive evidence.

Unsurprisingly, veterans who developed unexplained medical symptoms after the war attributed these symptoms to, among other things, their chemical and biological warfare exposure (Jones et al., 2002). Numerous studies have confirmed a correlation between chemical and biological warfare exposure beliefs and symptom reports (Boyd et al., 2003; McCauley et al., 2001; Nisenbaum et al., 2000; Proctor et al., 1998; Unwin et al., 1999; Wolfe et al., 1998). Although the pattern of unexplained symptom reports among the veterans is somewhat consistent with chemical and biological exposures (Fullerton \& Ursano, 1990; Haley \& Kurt, 1997; Proctor et al., 1998), it is also consistent with other explanations. Furthermore, most of what we know of the agents, especially biological ones, relates to acute illness episodes and almost all veterans deny having had such episodes.

Studies by our group and others have established that psychiatric conditions do not account for the excess of symptoms. Gulf War veterans have higher levels of posttraumatic stress disorder (PTSD), depression, and anxiety disorder than non-Gulf War veterans (Fiedler et al., 2006), but these diagnoses do not account for the elevated symptoms among Gulf War veterans (Ismail et al., 2002).

The dearth of medical evidence caused us to contemplate a psychological source, as explicated by the symmetry rule, for variability in Gulf War veterans' enduring, unexplained symptoms (Wolfe et al., 1998). To be clear, we are interested in examining how exposure beliefs and symptoms come to be linked over time. Our approach is not necessarily inconsistent with actual chemical exposure having initially prompted some symptoms (although we find the evidence for such exposure unconvincing). Instead, we are interested in the evolution of the symptom-label symmetry over time.

The symptoms-to-label components of the symmetry rule have been typically thought of as being driven by the search for a new label. However, in the present study, the issue of chemical and biological warfare exposure is not new, being an event that happened years before. Because of the uncertainty surrounding chemical and biological warfare in the Gulf War, changes in belief may represent new information that came to light since they returned home. Changes in exposure beliefs may also point to a more general memory error (Koriat et al., 2000; Reyna \& Lloyd, 1997). That is, veterans may find their presently experienced symptoms to be more salient than the more distant experiences in the war. A desire for selfconsistency (McGuire, 1960) may prompt them to revise their beliefs about exposure to be 
congruent with their present symptomatic experience. The latter would be supported if there were a general change in many war-related beliefs that extend beyond chemical and biological warfare.

The symmetry rule also suggests that belief in chemical warfare exposure leads to new and enduring symptoms. Chemical warfare alerts were used in the Gulf War to alert soldiers to the possible presence of chemical warfare agents and veterans recall the alerts as having been relatively frequent (Brewer et al., 2006). The alarms provided a label of "exposed" that, for some, has endured long after the all-clear was sounded (Gilbert et al., 1990; Lord et al., 1979; Ross et al., 1975). This new label could cause the soldiers to be more attentive to existing and new symptoms that were consonant with their belief about exposure, making the symptoms more enduring.

The study examined the two hypotheses, that symptoms lead to labels and the more interesting possibility that labels give rise to new symptoms, in a seven-year longitudinal study of Gulf War veterans. The events that passed during the war itself are lost to history, but it is still possible to follow these veterans over time and examine how changes in symptoms and changes in beliefs about chemical warfare exposure are related. The longitudinal aspect of the present study allowed us to tease apart the two causal pathways. This offers a refinement of the previous work in this area, including our own, that employed cross-sectional analyses that confounded the two hypotheses. We tested these hypotheses using structural equation modeling, an analytic approach that has many advantages. The one most central to our objectives is the ability to test the two hypotheses simultaneously. Past studies that have related multiple reported exposures to symptoms have examined separately the effects of each exposure (e.g., Boyd et al., 2003; Proctor et al., 1998). Their approach leaves unanswered the question of whether, after controlling for the initial symptomexposure correlation, recalled exposures explain unique variance in latter symptom reports and whether symptom reports predict later recalled exposure.

\section{METHOD}

\subsection{Participants}

The Department of Veterans Affairs provided a random sample from a national registry of American veterans with concerns about medical problems they believe resulted from their service in the Persian Gulf War. The sample was restricted to veterans who resided within states that had direct, proximate travel access to the West Orange, NJ Veterans Administration hospital (i.e., Delaware, Illinois, New Jersey, New York, North Carolina, Ohio, and Pennsylvania). They were interviewed in 1995, 2000, and 2002 as part of a longitudinal study. The detailed methods of these three interviews have been published previously (Hallman et al., 2003; Fiedler et al., 2006; Brewer et al., 2006, respectively). In brief, we selected 505 veterans who we had interviewed in 1995 to be interviewed again in the fall of 2002. Three were ineligible due to health reasons or death, 117 could not be contacted, and 23 refused to participate in the study. The resulting sample $(n=362)$ reflected a response rate of $72 \%$ and a cooperation rate of $94 \%$ relative to the 2000 interview. The veterans interviewed were primarily white $(83 \%)$, male $(92 \%)$, moderately well educated (30\% reported having a college degree in 2000$)$, enlisted (88\%), and mostly 
middle-aged (mean 43 years). Compared to nonrespondents, study participants were more likely to be older $(t(503)=2.80, p<0.05)$, white $\left(83 \%\right.$ vs. $\left.73 \%, \chi^{2}=7.22, p<0.05\right)$, and to have reported moderate or severe medical symptoms at the initial interview $(t(503)=3.01, p$ $<0.05$ ), but they did not differ on other variables including sex, level of education, rank, branch of military, having been wounded in the war, or number of medical conditions.

\subsection{Measures and Procedure}

In the 1995 (time 1) interview, participants completed a mail survey that included questions about their medical symptoms, their war-related exposures, demographic variables, and other topics not examined here (Hallman et al., 2003; Boyd et al., 2003). The 2002 (time 2) interviews were conducted by telephone, lasted for approximately 45 minutes $(M=46, S D=$ 17 ) and concerned the same symptoms and exposure topics as the time 1 interview. Data from the 2000 interview are not reported because recall of war exposures was not assessed.

2.2.1. Control Variables-We collected data on 10 variables that might provide an alternative explanation for the relationships we sought to examine. Except as noted, all were assessed at time 1. Race, sex, socioeconomic status (SES), having been wounded in the war, and believing that they had an illness caused by Gulf War service were coded as dichotomous variables. Age, disease burden (number of 38 possible diagnoses), additional diagnoses in the two years immediately prior to time 2, PTSD symptoms, and combatrelated stressors were coded as continuous variables. To characterize SES, a composite variable combining education level and military rank (a proxy for income) was created. This approach also addressed the issue of rank and education being strongly correlated (Spearman's $r=0.55, p<0.001$ ). Education level was an ordinal variable indicating approximate years of schooling and rank was a three-level ordinal variable indicating whether the veteran had been enlisted, a warrant officer, or a commissioned officer. A $k$ means cluster analysis was conducted to create two SES clusters based on rank and education. One third of the overall sample (34\%) clustered into the higher SES cluster. Veterans who had witnessed a traumatic event during the war completed the impact of events scale (Horowitz et al., 1979) that measures attempts to avoid, over the week prior to filling out the questionnaire, reminders of the trauma and intrusive thoughts or affective experiences common to PTSD. Two subscales were calculated for avoidant thoughts and for intrusive thoughts. Approximately one-third of the sample had experienced no traumatic events and thus were assigned values of zero on the scales. To eliminate the skewing, two new variables were constructed that each had three levels. Veterans with no traumatic experiences received a "1"; those below the median received a "2"; and those above the median received a "3." The resulting scales were highly correlated $(r=0.88)$ and so were averaged together to create a single score. Combat experiences were assessed using an eightitem scale that included items such as "Get fired upon" and "Fire at enemy forces" (Boyd et al., 2003; Gallops et al., 1981).

2.2.2. War Exposures-Four domains of war-related exposures were assessed at times 1 and 2 using scales described by Boyd et al. (2003) or slight modifications thereof. Exposure to chemical and biological warfare was assessed using a two-item scale (time 1, $\alpha=0.83$; time $2, a=0.73$ ). An additional item about radiological warfare reported by Boyd et al. was 
not used because few people had endorsed the item and it was the lowest loading item on the scale. Exposure to contamination was assessed using a five-item scale $\left(a_{\mathrm{T} 1}=0.64, \mathrm{a}_{\mathrm{T} 2}=\right.$ 0.58). Items included exposure to "contaminated or unsafe food," and "communicable diseases." Boyd et al. reported an additional item assessing exposure to microwaves that was not included here because few people endorsed the item and it was the lowest loading item on the scale. Exposure to harsh desert conditions was assessed using a seven- or five-item scale $\left(a_{\mathrm{T} 1}=0.73, a_{\mathrm{T} 2}=0.64\right)$. Three of the items used at time 1 ("harsh sunlight," "very hot or cold temperatures," and "blowing sands") were replaced by a single, conceptually similar item at time 2 ("bad climate or harsh weather"). The other items in the scale were not changed between the two interviews. Exposure to deprivation experiences was assessed using a three-item scale $\left(a_{\mathrm{T} 1}=0.58, a_{\mathrm{T} 2}=0.67\right)$. Items included "not having enough to eat" and "having a hard time keeping clean." Continuous scores were used in the scale construction. Responses were also scored dichotomously $(1=$ self-report of exposure; $0=$ no self-report of exposure) to simplify the reporting of changes over time in Table I.

2.2.3. Medical Symptoms-Hallman et al. (2003) established four symptom factors that characterize Gulf War veterans' unexplained medical problems: mood/memory/fatigue, musculoskeletal, gastrointestinal, and throat/breathing (Fukuda et al., 1998). To assess these, participants were asked at times 1 and 2 whether they had persistent or recurring problems in the last six months with any of Hallman et al.'s 48 medical symptoms and, if so, to report whether each problem was mild, moderate, or severe. Composite scores representing total number of moderate or severe symptoms from each of the four symptom factors reported at each time period were calculated. The mood/memory/fatigue factor (Chronbach's $\mathrm{a}_{\mathrm{T} 1}=$ $0.92, \mathrm{a}_{\mathrm{T} 2}=0.93$ ) contained 12 symptoms (e.g., "fatigue not due to exercise"). The musculoskeletal factor $\left(\mathrm{a}_{\mathrm{T} 1}=0.87, \mathrm{a}_{\mathrm{T} 2}=0.88\right)$ contained six symptoms (e.g., "pain in arms or legs"). The gastrointestinal factor $\left(a_{\mathrm{T} 1}=0.79, \mathrm{a}_{\mathrm{T} 2}=0.82\right)$ contained seven symptoms (e.g., "abdominal pain"). The throat/breathing factor $\left(a_{\mathrm{T} 1}=0.64, \alpha_{\mathrm{T} 2}=0.76\right)$ contained four symptoms (e.g., "difficulty swallowing"). A composite score $\left(a_{\mathrm{T} 1}=0.89, \mathrm{a}_{\mathrm{T} 2}=0.85\right)$ was also created for the remaining symptoms not otherwise included in a factor (e.g., "sweating not due to exercise"). To correct for the skewing that is common in count variables, the symptom summary scores were log transformed prior to being used in statistical analyses.

\section{RESULTS}

\subsection{Descriptive and Bivariate Analyses}

Table I shows the agreement over time in recall of war exposures. The most striking trend is that all exposures recalled declined over time. The number of yes-to-no changes sharply exceeded the number of no-to-yes changes with a mean decline of $30 \%$. The largest decliners-self-reports of biological warfare, smoke from cigarettes, and smoke from space heaters-were no longer endorsed by half of the veterans. The smallest decliners-selfreports of not having enough to drink, having a hard time keeping clean, and faulty safety equipment-were no longer endorsed by $20 \%$ of the veterans.

Veterans reported a relatively small increase in symptoms at follow-up. They reported an average of one additional symptom $(M=11.2$ vs. 12.3 , of 48 possible symptoms, $\mathrm{SE}=0.40)$ 
between time 1 and time 2 . This was largely due to a slight increase in "other" symptoms reported, $(M=3.7$ vs. 4.4 , of 12 possible symptoms, $\mathrm{SE}=0.16), t(361)=3.04, p<0.05$. This change is likely due to the normal effects of aging over the seven-year span as it is confined to the "other" symptoms that are not commonly associated with Gulf War service (Fukuda et al., 1998; Hallman et al., 2003). There were no significant differences in the $\mathrm{mood} / \mathrm{memory} /$ fatigue symptoms $(M=3.5 \mathrm{vs} .3 .7$, of 12 possible, $\mathrm{SE}=0.14)$, musculoskeletal symptoms ( $M=2.2$ vs. 2.3 , of 6 possible symptoms, $\mathrm{SE}=0.09$ ), gastrointestinal symptoms ( $M=1.3$ vs. 1.3 , of 7 possible symptoms, $\mathrm{SE}=0.08$ ), or throat/ breathing symptoms $(M=0.5$ vs 0.6 , of 4 possible symptoms, $\mathrm{SE}=0.05)$.

The symmetry rule's predictions about the reciprocal relationships between self-reported symptoms and war exposures received preliminary support from the bivariate correlations of the two. Indeed, all of the 60 relevant correlations in Table II are significant. Cross-sectional tests of the symmetry rule, underlined in Table II, show that war-related exposures and medical symptoms reports were correlated within each time period. Similarly, the "bold" correlations show the longitudinal correlations between symptoms and war-related exposures. The table provides an apt summary of much of the research in this area to date: pretty much everything is related to everything else. It also highlights the need for a theoretical model to organize the multiple, overlapping relationships.

\subsection{Confirmatory Analysis}

Our approach was first to conduct a confirmatory factor analysis to see whether the latent variables we stipulated were statistically tenable. This analysis restricts the pathways in the model by specifying that most observed variables are related only to latent variables, but specifies all possible correlations among latent variables and any observed variables not loading on a latent variable. Next, we performed structural equation modeling. This analysis constrained the confirmatory model, by eliminating some pathways and by converting others to causal pathways.

For the confirmatory analysis, we specified a latent variable for medical symptoms (indicating the observed symptom variables for mood/memory/fatigue, musculoskeletal, gastrointestinal, throat/ breathing, and other), an observed variable for chemical and biological warfare exposures because we did not expect it to load on any latent variable, and a latent variable for the remaining war-related exposures (indicating the observed exposure variables for contamination, harsh desert conditions, and deprivation) for each time point. The loadings of observed variables on latent factors (see first two columns of Table III) are of particular interest because they reflect the constrained part of the model. As is customary, but not of central interest for the confirmatory analysis, correlations were specified between error terms for time-lagged observed variables (see last column of Table III), and correlations were specified among all latent variables as well as the observed chemical/ biological warfare variables that were not part of any latent variable (see bottom of Table III).

A good fit is indicated by a comparative fit index (CFI) greater than 0.95 , root mean square for error (RMSEA) less than 0.05, and a nonsignificant chi-square statistic. The fit indices for the model suggested that that it fit the data well, $\mathrm{CFI}=0.990$; $\mathrm{RMSEA}=0.028 ; \chi^{2}(114$, 
$N=362)=146.24, p<0.03$. Although the significant chi-square indicates some level of misfit to the data, such a finding is common for models with many variables and relatively large sample sizes as in the present study (Cochrane, 1952; Bentler \& Bonnet, 1980). The chi square is sensitive to sample size and model complexity and tends to increase with each. In contrast, RMSEA and CFI tend to be better measures of fit for models such as ours. An inspection of the modification indices indicated that the error terms for throat/breathing symptoms at time 1 and recollection of harsh desert conditions at time 2 should be allowed to covary $(\beta=-0.13)$, as should the error terms for gastrointestinal symptoms at time 1 and recollection of contamination at time $2(\beta=0.14)$. Although doing so caused the fit indices to improve slightly, $\mathrm{CFI}=0.992 ; \mathrm{RMSEA}=0.024 ; \chi^{2}(112, N=362)=135.98$, n.s., we elected not to make the change because it lacked a theoretical justification. Because the results we report below for the structural model did not change meaningfully if the pathways were added, they are not discussed further.

\subsection{Structural Model}

The data were fit to the structural model shown in Fig. 1. The model had good fit indices, $\mathrm{CFI}=0.988 ; \mathrm{RMSEA}=0.030 ; \chi^{2}(115, N=362)=152.40, p<0.05$. The model was rerun controlling for the 10 covariates described in Section 2, CFI $=0.978$; RMSEA $=0.031 ; \chi^{2}$ $(236, N=362)=317.15, p<0.001$. Although the chi square changed substantially, the other indices did not change appreciably and still showed a very good fit for the model. More importantly, the longitudinal pathways were virtually unchanged. For the sake of simplicity, Fig. 1 shows path coefficients adjusted for control variables, but does not show pathways involving control variables or noncausal pathways carried over from the confirmatory analysis.

As predicted, higher initial symptom reports led to relatively higher later exposure recall. This was true for recall of both chemical/biological warfare exposure and other exposures. The model predicted $27 \%$ of time 2 chemical/biological warfare exposure recall. This measure was predicted equally well by previous reports of the same exposures $(\beta=0.29, p<$ $0.001)$ as by time 1 symptom reports $(\beta=0.32, p<0.001)$. The model predicted $41 \%$ of time 2 other exposure recall. This measure was predicted better by previous reports of the same exposures $(\beta=0.46, p<0.001)$ than by time 1 symptoms $(\beta=0.21, p<0.001)$. Because of the substantial drop in exposure recall over time, the positively signed symptom-exposure relationships can be interpreted as follows: those with more initial symptoms continued recalling they had been exposed while exposure recall fell away for those with fewer initial symptoms.

To a lesser extent, higher initial recall of exposure led to relatively higher symptom reports later in time. The model predicted $64 \%$ of symptoms reported at time 2 . Time 1 chemical/ biological warfare exposure recall predicted symptoms at time $2(\beta=0.15, p<0.05)$, but time 1 other exposure recall did not $(\beta=-0.04$, n.s.). These small coefficients may reflect the high stability of symptom reports over time $(\beta=0.71, p<0.001)$ that left relatively little variance unexplained. Because there were minimal changes in symptoms on average, the positive exposure-symptom relationship is possible only if those veterans with lower initial 
exposure beliefs experienced a drop in symptoms that offset an increase in symptoms among those with higher initial exposure beliefs.

\section{DISCUSSION}

The present research sought to find empirical support for the symmetry rule (Leventhal et al., 1980) in the context of the medical symptoms reported by Gulf War veterans. The rule predicts that symptoms cause people to seek and find an explanatory label. It also predicts that having an illness or exposure label causes people to seek and find symptoms.

There is clear support for the symmetry rule's first prediction. Veterans with more health symptoms were more likely to recollect exposure to chemical and biological warfare as well as to war-related stressors. This finding should be carefully interpreted given that exposure recall mostly declined between 1995 and 2002. A more elaborate but descriptive summary of the findings is: the less symptomatic veterans tended to stop recalling they were exposed, but the symptomatic veterans were more likely to continue recalling exposure.

We found less support for the symmetry rule's second prediction that exposure labels would lead to higher symptom reports. Greater chemical/biological warfare exposure recall was related to greater later symptom reports. Recalling other exposures was unrelated to greater symptoms at follow-up. The finding suggests that at least some portion of veterans' symptoms may be explained by the beliefs they hold. The effect appears to be small and general in nature, however, and was not specific to Gulf War typical symptoms. Thus, we conclude that, although some variability in the veterans' symptoms is related to their fallible recall of exposures, it does not explain why veterans have a disproportionately large number of unexplained symptoms.

The longitudinal relation of symptoms and labels are similar to those reported by King et al. (2000) in a study of Gulf War veterans (see also Southwick et al., 1997; Wyshak, 1994).

Among male veterans, initial PTSD symptoms predicted slightly increased recall of combat stressors a year and a half later and initial recall of combat stressors predicted novel PTSD symptoms ( $\beta \mathrm{s}=0.07$ and 0.08 ). The effects we report are quite a bit larger $(\beta \mathrm{s}=0.15$ to 0.32), but this may reflect the longer time frame of our study (seven years rather than just under two years) and the different measures used. However, the present study puts the previous PTSD-traumatic memory findings in a broader context that incorporates veterans' health symptoms and noncombat war-related exposures.

A final issue is the stability of the measures over time. Symptom reports showed a very strong relationship over time ( $\beta=0.71)$ and little mean change. The high stability of symptoms reports is not surprising in that they reflect current experience (and to a small extent the ability to recall symptoms from the past six months). Three findings taken together - the stability of symptoms, their resistance to the influence of prior beliefs, and the symptom-general effect of such prior beliefs—suggests that the symmetry rule explains a small portion of the higher number of symptoms reported by Gulf War veterans relative to other veterans. A study conducted closer to the war itself may have yielded different 
findings. Stressors experienced acutely during the war may invoke symmetry-rule-like processes to a larger extent, but this speculation was not addressed by the present study.

Other war-related exposure recollections were intermediate in their stability $(\beta=0.46)$ with moderate declines, and measures of chemical and biological warfare exposure were the least stable $(\beta=0.29)$ with the largest decline in recall. The lower overall stability for the exposure measures is partially a reflection of having to recall events from a long time ago and partially a reflection of the susceptibility of such memories to other influences such as previous symptom experiences. The lowest stability for chemical or biological warfare exposure beliefs is related in part to newly established facts about the absence of chemical and biological warfare agents in the Gulf War. Overall, the substantial drop in all exposure beliefs suggests that the fragility of memory played a larger role than the revelation of new information (Murphy et al., 2008).

The 30\% drop in exposure beliefs we report is different in direction and magnitude from similar previous studies (Wessely et al., 2003). King et al. (2000) reported a 10\% increase in recalled incidences of combat stressors among 2,492 Gulf War veterans interviewed shortly after their return and again 18 to 24 months later. Southwick et al. (1997) reported a similar $12 \%$ increase in recalled incidences of combat stressors among 59 Gulf War veterans interviewed one month after their return and again 24 months later. The studies differ in that we examined a very long time lag that began well after the war ended, whereas King's and, Southwick and colleagues' studies considered shorter time frames (no longer than three years) that were closer to the end of war itself. The differences may reflect an underlying curvilinear function such that veterans ruminate and elaborate on the their war memories shortly after the war but these elaborations subsequently fade over longer periods of time.

The study has several limitations. The longitudinal findings can be meaningfully interpreted only in the absence of influential unmeasured variables that are themselves changing over time. Were this the case, then spurious longitudinal findings could be found. To address this potential problem, we controlled for several of the most likely variables such as disease burden and changes in disease. The study variables were all based on self-report. We believe the method was appropriate given that Gulf War veterans' unexplained medical problems are defined not by objective tests but by their self-reports of disability. Time 1 interviews were conducted by mail, and time 2 were conducted by phone. The two methods can yield different answers, for example, with people reporting fewer symptoms by phone (Brewer $e t$ al., 2004). The drop in exposure reports may reflect this, although the lack of an appreciable drop in symptoms makes this less likely. We studied a random sample of veterans that became to some extent self-selected because of their opting in to the Gulf War Registry. Our other research has shown several findings that generalized from this Registry sample to a random sample of all Gulf War veterans, and a random sample of all Gulf War era veterans not deployed to the Gulf (Brewer et al., 2006). Such findings give us reason to expect that the results of the present study are generalizable to other veteran populations. Most respondents were white and male, and respondents were more likely to be white older veterans who reported more serious symptoms at time 1 than nonrespondents, potentially limiting the generalizability of the findings to other groups. The findings' generalizability to 
nonveteran populations and to populations that are not primarily male and white is unknown at this point.

In summary, symptoms led veterans to maintain their recall of exposure to various dangers during the Persian Gulf War. Only initial chemical and biological warfare exposure recall longitudinally predicted subsequent changes in symptoms. Problems triggered by illness and exposure labels may extend beyond the battlefield. Returning to our earlier example of genetically modified corn, merely coming to believe that one is exposed can impact the symptoms that one ascribes to the exposure. Taco shells, even genetically modified ones, are benign relative to chemical warfare, yet there appear to be similar ways that people integrate the risk information for the two. Another example is false positive medical tests that may encourage some patients to become symptomatic as they search for symmetry between the label and their bodily experiences. Indeed, a recent meta-analysis found that women who receive false-positive mammograms experience enduring, elevated levels of anxiety and conduct more frequent breast self-exams, even well after they have been informed that the initial positive test was an error (Brewer et al., 2007). These findings should draw the attention of public health and government officials to how they communicate about periodic uncertainties such as a food recall, medical test results, or unconfirmed anthrax exposure. Heightening the public's concern may strengthen preparedness, but it may come at the cost of increased self labeling, label-consistent attribution of medical symptoms, and spikes in use of the health care system. Symptoms are very real for the people who suffer from them.

\section{Acknowledgments}

The study was supported by grants awarded to Dr. Hallman by the Department of Veterans Affairs and the Centers for Disease Control and Prevention (\#U50/CCU214463-01); Dr. Kipen by the National Institute of Environmental Health Sciences (\#ES05022), and Dr. Brewer by the American Cancer Society (MSRG-06-259-01-CPPB). We thank Kendal Boyd, Sarah Condry, Nancy Fiedler, Srinivas Maloor, Gozde Ozakinci, and Daniel Wartenburg for their work on the project and two anonymous reviewers for their comments on an earlier draft. Portions of this article were presented at the 2003 Annual Conference of the Society for Behavioral Medicine, Salt Lake City, UT.

\section{REFERENCES}

Barsky A, Borus JF. Functional somatic syndromes. Archives of Internal Medicine. 1999; 130:910921.

Barsky AJ, Ettner SL, Horsky J, Bates DW. Resource utilization of patients with hypochondriacal health anxiety and somatization. Medical Care. 2001; 39:705-715. [PubMed: 11458135]

Barsky AJ, Klerman GL. Overview: Hypochondriasis, bodily complaints, and somatic styles. American Journal of Psychiatry. 1983; 140:273-283. [PubMed: 6338747]

Baumann LJ, Cameron LD, Zimmerman RS, Leventhal H. Illness representations and matching labels with symptoms. Health Psychology. 1989; 8:449-469. [PubMed: 2583080]

Baumann LJ, Leventhal H. I can tell when my blood pressure is up, can't I? Health Psychology. 1985; 4:203-218. [PubMed: 4029105]

Bentler PM, Bonnet DG. Significance tests and goodness of fit in the analysis of covariance structures. Psychological Bulletin. 1980; 88:588-606.

Blumhagen D. Hyper-tension: A folk illness with a medical name. Culture, Medicine, and Psychiatry. 1980; 4:197-227.

Boyd KC, Hallman WK, Wartenberg D, Fiedler N, Brewer NT, Kipen HM. Reported exposures, stressors, and life events among Gulf War Registry veterans. Journal of Occupational and Environmental Medicine. 2003; 45:1247-1256. [PubMed: 14665810] 
Brewer NT, Chapman GB, Brownlee S, Leventhal E. Cholesterol, adherence, and illness cognition. British Journal of Health Psychology. 2002; 7:433-447. [PubMed: 12614495]

Brewer NT, Hallman WK, Kipen HM, Fiedler N. Why do people report better health by phone than by mail? Medical Care. 2004; 42:875-883. [PubMed: 15319613]

Brewer NT, Lillie SE, Hallman WK. Why people believe they were exposed to biological or chemical warfare: Reports from Gulf War veterans. Risk Analysis. 2006; 26:337-345. [PubMed: 16573624]

Brewer NT, Salz T, Lillie SE. The long-term effects of false-positive mammograms: A systematic review. Annals of Internal Medicine. 2007; 146:502-510. [PubMed: 17404352]

Brownlee, S.; Leventhal, H.; Leventhal, EA. Regulation, self-regulation, and construction of the self in the maintenance of physical health. In: Boekartz, M.; Pintrick, PR.; Zeidner, M., editors. Handbook of Self-Regulation. San Diego, CA: Academic Press; 2000. p. 369-393.

Centers for Disease Control and Prevention. [accessed July 30, 2006] Investigation of Human Health Effects Associated with Potential Exposure to Genetically Modified Corn. 2001. Available at http://www.cdc.gov/nceh/ehhe/Cry9cReport/cry9creport.pdf

Cioffi D. Beyond attention strategies: A cognitive-perceptual model of somatic interpretation. Psychological Bulletin. 1991; 109:25-41. [PubMed: 2006227]

Cochrane WG. The $\chi^{2}$ test of goodness of fit. Annals of Mathematical Statistics. 1952; 23:315-345.

Couzin J. Texas earmark allots millions to disputed theory of Gulf War illness. Science. 2006; 312:668. [PubMed: 16675667]

Croyle RT, Sande GN. Denial and confirmatory search: Paradoxical consequences of medical diagnosis. Journal of Applied Social Psychology. 1988; 18:473-490.

David A, Wessely S. The legend of Camelford: Medical consequences of a water pollution accident. Journal of Psychosomatic Research. 1995; 39:1-9. [PubMed: 7760298]

Fiedler N, Ozakinci G, Hallman WK, Wartenberg D, Brewer NT, Kipen HM. Military deployment as a risk factor for psychiatric illness. British Journal of Psychiatry. 2006; 188:453-459. [PubMed: 16648532]

Fukuda K, Nisenbaum R, Stewart G, Thompson W, Robin L, Washko R, et al. Chronic multisymptom illness affecting air force veterans of the Gulf War. JAMA. 1998; 280:981-988. [PubMed: 9749480]

Fullerton CS, Ursano RJ. Behavioral and psychological responses to chemical and biological warfare. Military Medicine. 1990; 155:54-59. [PubMed: 2106650]

Gallops, M.; Laufer, RS.; Yager, T. Part III, appendix 1: The combat scale revised. In: Egendorf, A.; Kadushin, C.; Laufer, RS.; Rothbart, G.; Sloan, L., editors. Legacies of Vietnam: Comparative Adjustment of Veterans and Their Peers. New York: Center for Policy Research; 1981. p. 125-129.

Gilbert DT, Krull DS, Malone PS. .Unbelieving the unbelievable: Some problems in the rejection of false information. Journal of Personality \& Social Psychology. 1990; 59:601-613.

Gray GC, Reed RJ, Kaiser KS, Smith TC, Gastanaga VM. Self-reported symptoms and medical conditions among 11,868 Gulf War-era veterans: The Seabee Health Study. American Journal of Epidemiology. 2002; 155:1033-1044. [PubMed: 12034582]

Gray GC, Smith TC, Knoke JD, Heller JM. The postwar hospitalization experience of Gulf War veterans possibly exposed to chemical munitions destruction at Khamisiyah, Iraq. American Journal of Epidemiology. 1999; 150:532-540. [PubMed: 10472954]

Haley RW, Kurt T, Horn J. Is there a GulfWar Syndrome? Searching for syndromes by factor analysis of symptoms. JAMA. 1997; 277:215-222. [PubMed: 9005271]

Hallman WK, Kipen HM, Diefenbach M, Boyd K, Kang H, Leventhal H, et al. Symptom patterns among Gulf WarRegistry veterans. American Journal of Public Health. 2003; 93:624-630. [PubMed: 12660208]

Hodgson MJ, Kipen HM. Gulf War illnesses: Causation and treatment. Journal of Occupational and Environmental Medicine. 1999; 41:443-452. [PubMed: 10390695]

Horowitz MJ, Wilner NR, Alvarez W. Impact of events scale: A measure of subjective stress. Psychosomatic Medicine. 1979; 41:209-218. [PubMed: 472086] 
Iowa Persian Gulf Study Group. Self-reported illness and health status among Gulf War veterans: A population-based study. JAMA. 1997; 277:238-245. [PubMed: 9005274]

Ismail K, Kent K, Brugha T, Hotopf M, Hull L, Seed P, Palmer I, Reid S, Unwin C, David AS, Wessely S. The mental health of UK Gulf War veterans: Phase 2 of a two phase cohort study. BMJ. 2002; 325:576. [PubMed: 12228134]

Jones E, Hodgins-Vermaas R, McCartney H, Everitt B, Beech C, Poynter D, Palmer I, Hyams K, Wessely S. Post-combat syndromes from the Boer War to the Gulf War: A cluster analysis of their nature and attribution. BMJ. 2002; 324:321-324. [PubMed: 11834557]

King DW, King LA, Erickson DJ, Huang MT, Sharkansky EJ, Wolfe J. Posttraumatic stress disorder and retrospective reported stressor exposure: A longitudinal prediction model. Journal of Abnormal Psychology. 2000; 109:624-633. [PubMed: 11195986]

Koriat A, Goldsmith M, Pansky A. Toward a psychology of memory accuracy. Annual Review of Psychology. 2000; 51:481-537.

Leventhal, H.; Meyer, D.; Nerenz, D. The common sense representation of illness danger. In: Rachman, S., editor. Medical Psychology. Vol. Vol. 2. New York: Pergamon; 1980. p. 7-30.

Lord CG, Ross L, Lepper MR. Biased assimilation and attitude polarization: The effects of prior theories on subsequently considered evidence. Journal of Personality \& Social Psychology. 1979; 37:2098-2109.

McCauley LA, Rischitelli G, Lambert WE, Lasarev M, Sticker DL, Spencer PS. Symptoms of GulfWar veterans possibly exposed to organophosphate chemical warfare agents at Khamisiyah, Iraq. International Journal of Occupational \& Environmental Health. 2001; 7:79-89. [PubMed: 11373050]

McGuire WJ. Direct and indirect persuasive effects of dissonance-producing messages. Journal of Abnormal and Social Psychology. 1960; 60:345-358.

Mechanic D. Social psychologic factors affecting the presentation of bodily complaints. New England Journal of Medicine. 1972; 286:1132-1139. [PubMed: 4553340]

Meyer D, Leventhal H, Gutmann M. Common-sense models of illness: The example of hypertension. Health Psychology. 1985; 4:115-135. [PubMed: 4018002]

Murphy D, Hotopf M, Marteau T, Wessely S. Multiple vaccinations, health, and recall bias within the UK Armed Forces deployed to Iraq. BMJ. 2008; 337:220.

Nisenbaum R, Barrett DH, Reyes M, Reeves WC. Deployment stressors and a chronic multisymptom illness among Gulf War veterans. Journal of Nervous \& Mental Disease. 2000; 188:259-266. [PubMed: 10830562]

Pennebaker, JW. The Psychology of Physical Symptoms. New York: Springer-Verlag; 1982. Perceptual processes I: Competition of cues; p. 169-171.

Pennebaker JW, Watson D. Blood pressure estimation and beliefs among normotensives and hypetensives. Health Psychology. 1989; 74:309-328.

Proctor SP, Heeren T, White RF, Wolfe J, Borgos MS, Davis JD, Pepper L, Clapp R, Sutker PB, Vasterling JJ, Ozonoff D. Health status of Persian Gulf War veterans: Self reported symptoms, environmental exposures and the effect of stress. International Journal of Epidemiology. 1998; 27:1000-1010. [PubMed: 10024195]

Reyna VF, Lloyd F. Theories of false memory in children and adults. Learning \& Individual Differences. 1997; 9:95-123.

Ross L, Lepper MR, Hubbard M. Perseverance in self-perception and social perception: Biased attributional processes in the debriefing paradigm. Journal of Personality \& Social Psychology. 1975; 32:880-892. [PubMed: 1185517]

Shapiro SE, Lasarev MR, McCauley L. Factor analysis of Gulf War illness: What does it add to our understanding of possible health effects of deployment? American Journal of Epidemiology. 2002; 156:578-585. [PubMed: 12226005]

Sigal L, Hassett AL. Contributions of societal and geographical environments to "chronic Lyme disease": A psychopathogenisis and aporology of a new "medically explained symptoms" syndrome. Environmental and Health Perspectives. 2002; 100:607-611. 
Southwick SM, Morgan CA, Nicolaou AL, Charney DS. Consistency of memory for combat-related traumatic events in veterans of Operation Desert Storm. American Journal of Psychiatry. 1997; 154:173-177. [PubMed: 9016264]

Unwin C, Blatchley N, Coker W, Ferry S, Hotopf M, Hull L, Ismail K, Palmer I, David A, Wessely S. Health of UK servicemen who served in Persian Gulf War. Lancet. 1999; 353:169-178. [PubMed: 9923871]

Wessely S. Ten years on: What do we know about the Gulf War Syndrome? Clinical Medicine. 2001; 1:28-37. [PubMed: 11358073]

Wessely S, Unwin C, Hotopf M, Hull L, Ismail K, Nicolaou, et al. Stability of recall of military hazards over time: Evidence from the Persian Gulf War of 1991. British Journal of Psychiatry. 2003; 183:314-322. [PubMed: 14519609]

Wolfe J, Proctor SP, Davis JD, Borgos MS, Friedman MJ. Health symptoms reported by Persian Gulf War veterans two years after return. American Journal of Industrial Medicine. 1998; 33:104-113. [PubMed: 9438043]

Wyshak G. The relation between change in reports of traumatic events and symptoms of psychiatric distress. General Hospital Psychiatry. 1994; 16:290-297. [PubMed: 7926706] 


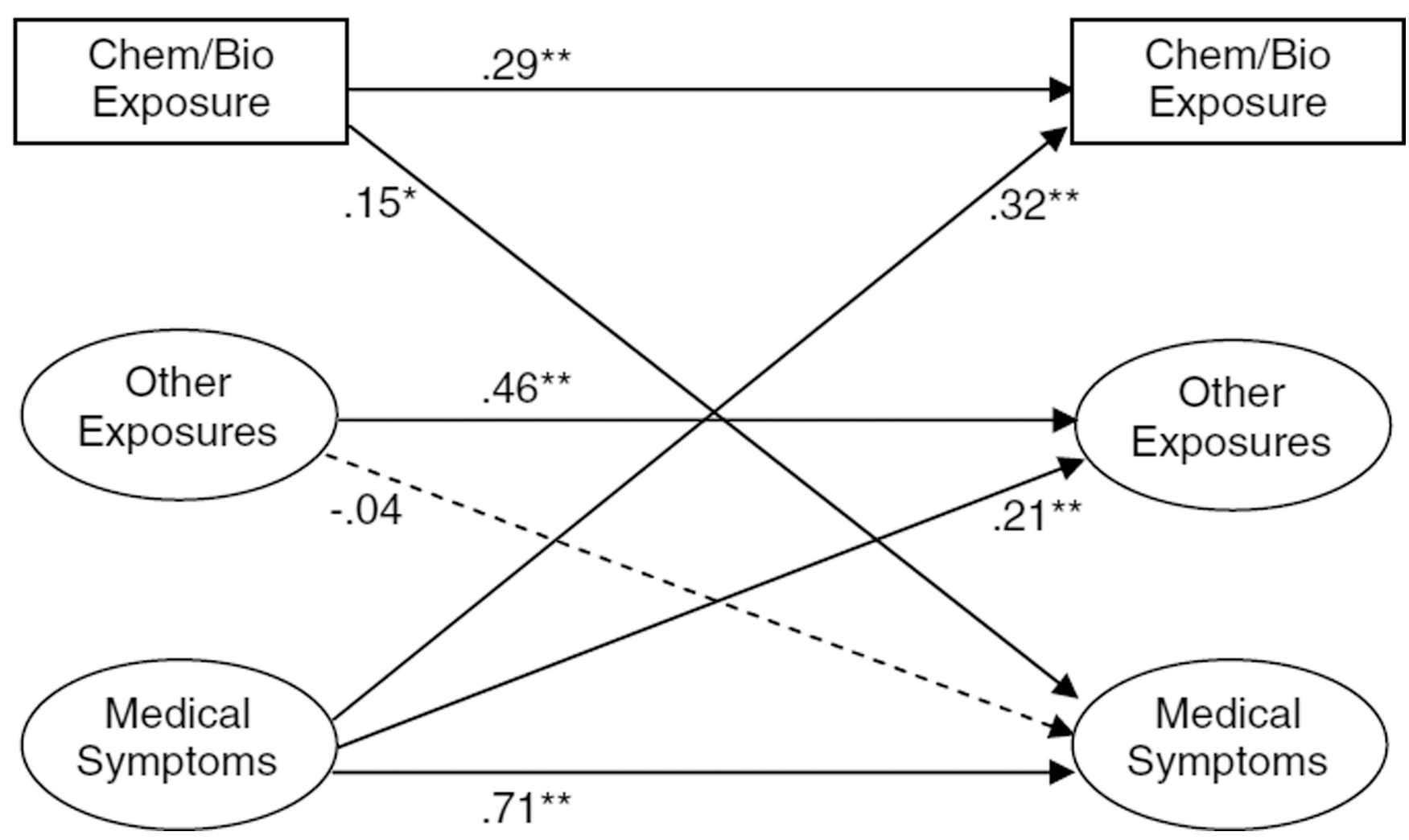

Fig. 1.

Structural model. The diagonal pathways test the symmetry rule. The hypothesis that symptoms give rise to explanatory labels was supported. The converse hypothesis, that explanatory labels give rise to symptoms, was partially supported. For the sake of visual clarity, the diagram shows only causal pathways whose coefficients are adjusted for control variables, but not the control variables, the correlations of variables within time periods, or the time-lagged correlations of observed variables' error terms in the measurement models (see Table III). $* * p<0.001, * p<0.05$. 


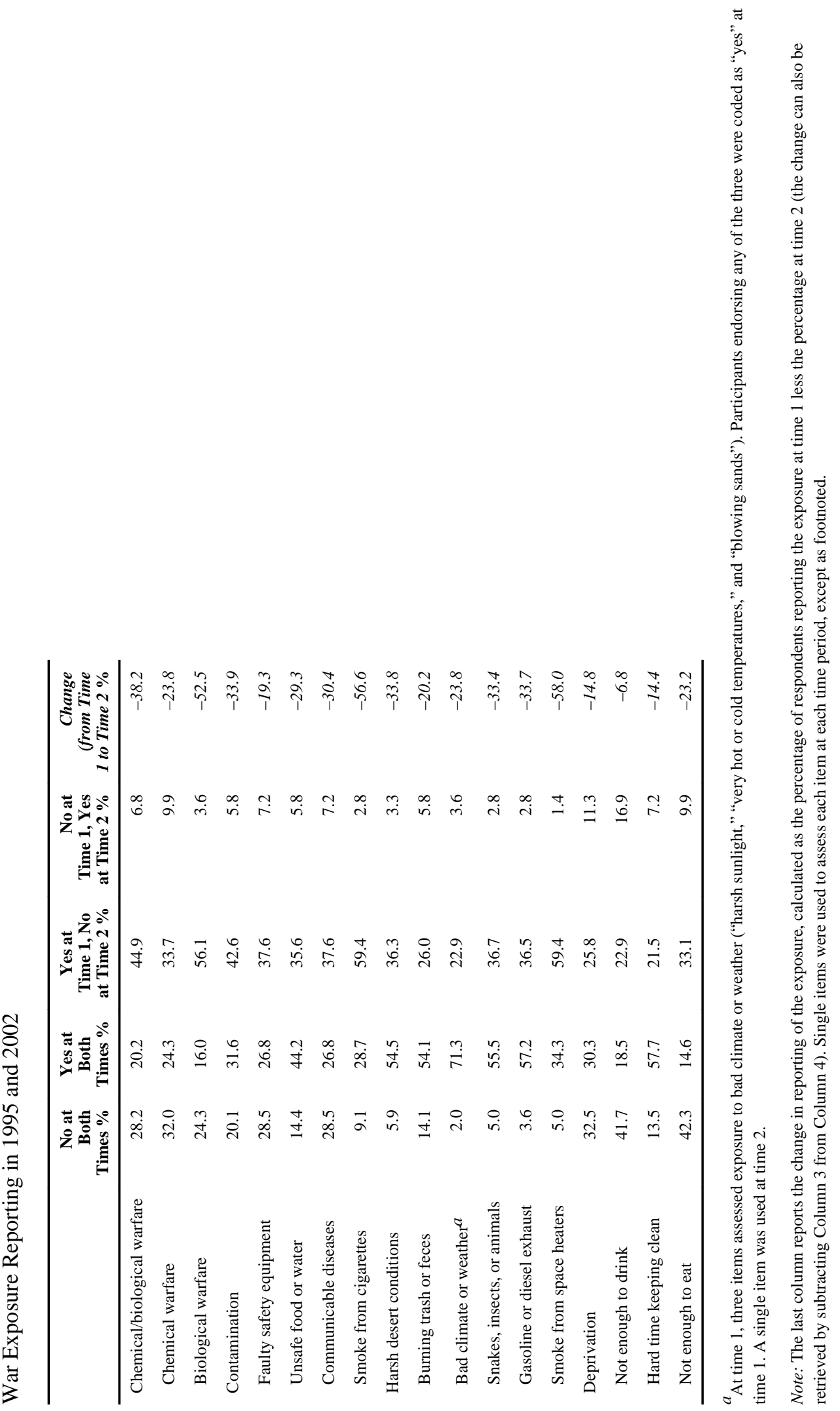




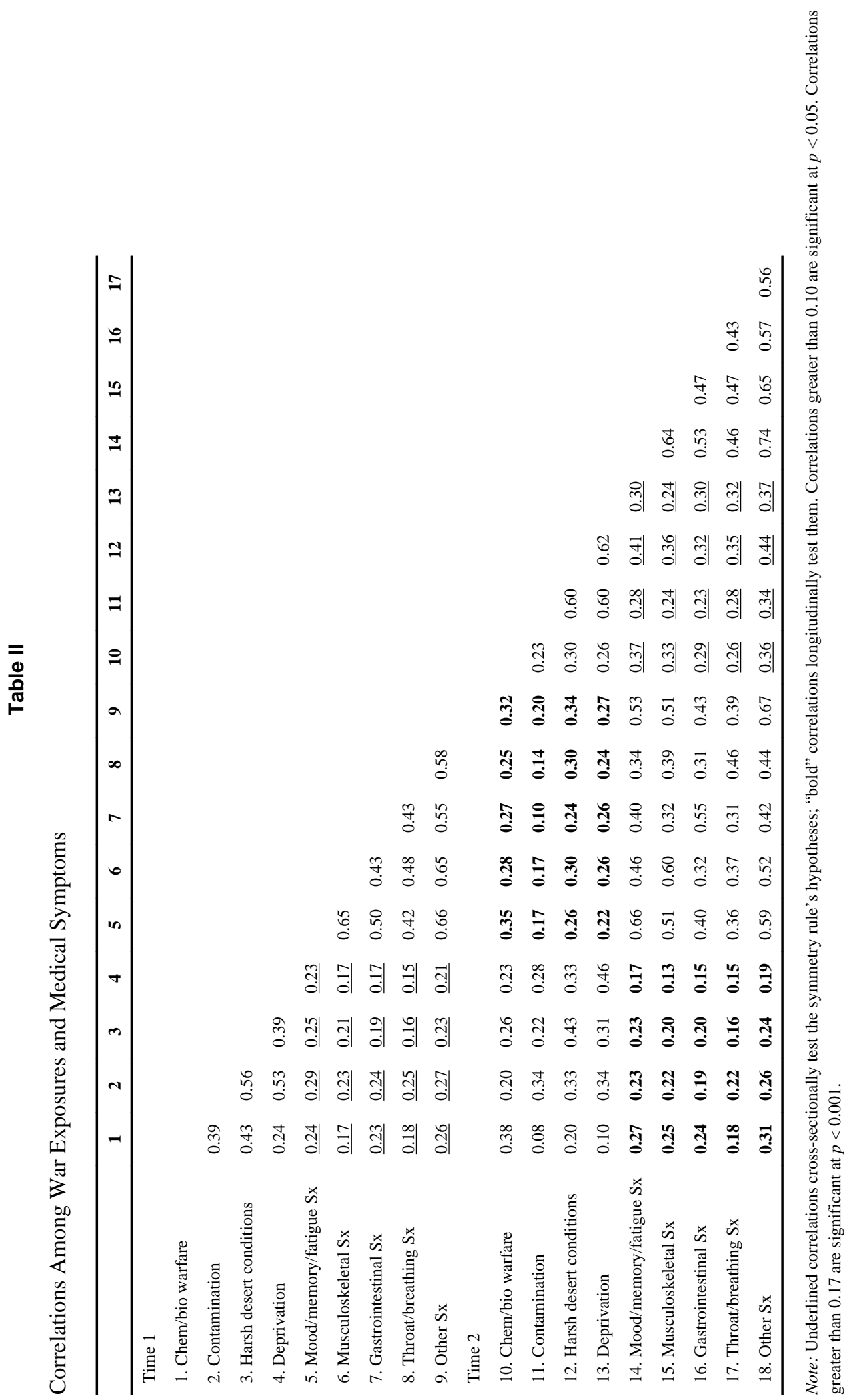




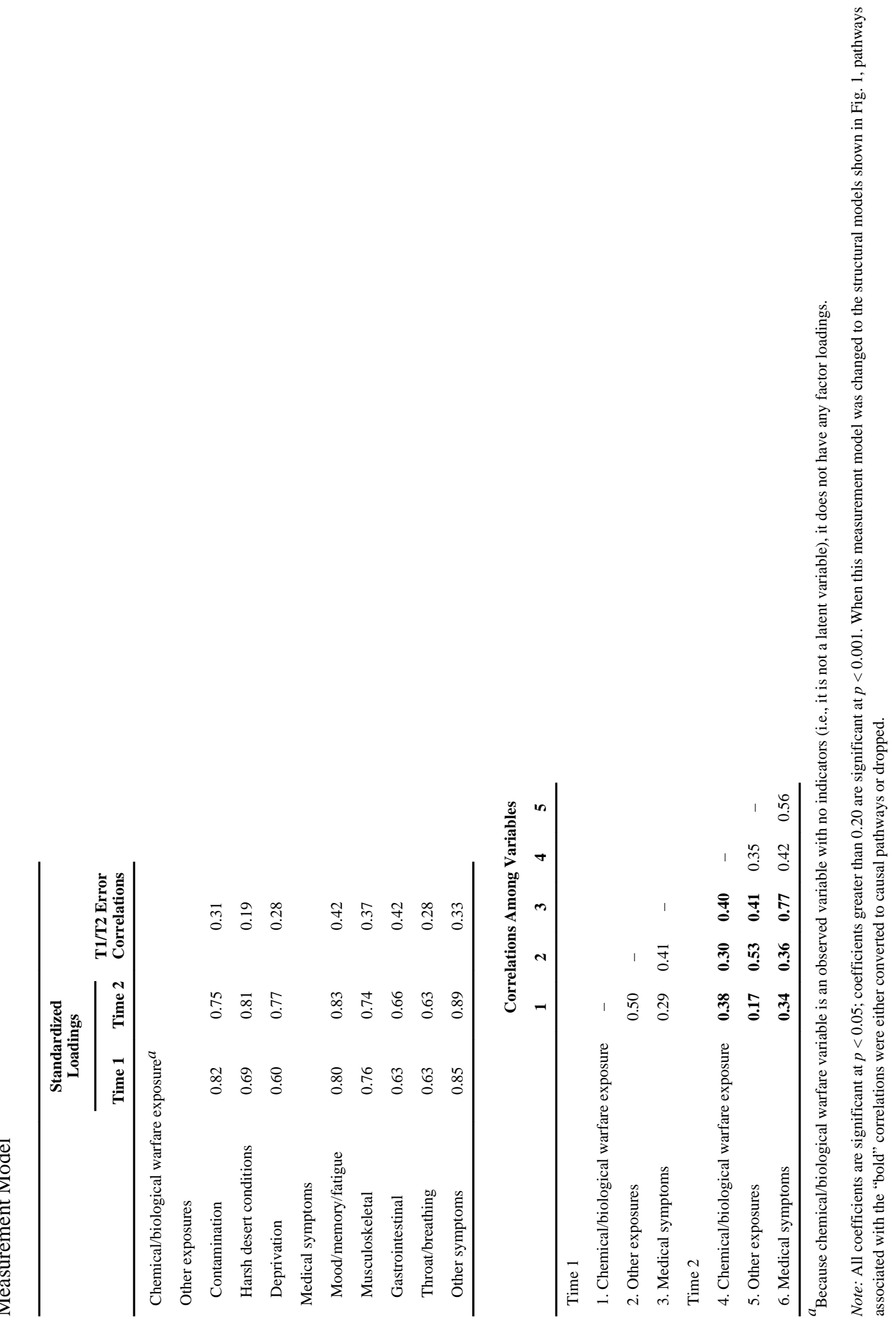

